\title{
The role of recombinant human DNase in the treatment of patients with cystic fibrosis: many promises, more problems
}

\author{
Maximilian S Zach
}

The median survival of patients with cystic fibrosis at present approaches 30 years. ${ }^{1}$ Essentially, the ongoing medical and scientific struggle towards further improving this prognosis relies on the continued search for new treatment strategies and novel therapeutic substances. A relatively recent development is recombinant human DNase (rhDNase). The clinical efficacy of rhDNase has been discussed at scientific and educational meetings for several years, and it has been introduced into the therapeutic routine of many cystic fibrosis centres via large multicentre clinical trials. Thus, most cystic fibrosis caregivers have had ample opportunity to familiarise themselves with rhDNase, its safety profile, and its therapeutic effects.

Encouraging short term improvements in lung function, hopes that focus on any new and promising development, and considerable interest and pressure from cystic fibrosis lay organisations have motivated many centres to support national registration and to prescribe rhDNase to their cystic fibrosis patient populations. On closer scrutiny, however, there remains a spectrum of as yet unanswered questions regarding the long term effectiveness of rhDNase, indications for a more targeted prescription, and possible interactions with other treatment strategies. Recently published review articles either emphasise the problems or the promises of this new treatment strategy and thus differ substantially in their messages. ${ }^{23}$ This review, written from a clinical perspective, analyses the available data to achieve a more balanced view on the present role of rhDNase in the management of patients with cystic fibrosis.

Respiratory and
Allergic Disease
Division,Paediatric
Department,
University of Graz,
Austria
M S Zach
Correspondence to:
Professor Dr M S Zach,
KIinische Abteilung für
Pulmonologie/Allergologie,
Universitätsklinik für
Kinder- und
Jugendheilkunde,
Auenbruggerplatz 30,
A-8036 Graz, Austria.
Received 4 December 1995
Accepted for publication
22 January 1996

Respiratory and Allergic Disease Department, University of Graz, Austria

M S Zach

Correspondence to: KIinische Abteilung für Pulmonologie/Allergologie, Universitätsklinik für Jugendheilkunde, Auenbruggerplatz 30, content. ${ }^{4-10}$ It was shown that high levels of lung infection in cystic fibrosis are associated with markedly raised sputum DNA levels which mainly stems from the patient's own neutrophils. ${ }^{81011}$ Some of the earlier work had already shown that the rheological properties of sputum from patients with cystic fibrosis in cystic fibrosis largely depend on their DNA could be altered by adding DNase. ${ }^{41213}$ This again indicated the possibility of a new therapeutic strategy for improving the clearance of mucus from the airways of patients with cystic fibrosis.

Clinical studies with bovine DNase commenced as early as 1953. ${ }^{14-17}$ These trials, however, were subsequently stopped because of significant adverse effects. ${ }^{18}$ Human DNase, an enzyme normally produced in the pancreas and salivary glands, was first successfully cloned, sequenced, and expressed in $1990 .{ }^{19}$ Clinical studies with this recombinant human DNase started in 1992 and results from the first phase 1 trials, conducted to determine the tolerance to rhDNase and to gather basic pharmacokinetic data, were published in $1992 .{ }^{2021}$

Meanwhile, the safety profile of the substance has been well established. Inhalation of rhDNase seems to have no serious side effects; an increased incidence of voice alterations, laryngitis, pharyngitis, dyspepsia and facial oedema has been observed in patients treated with rhDNase. ${ }^{322-24}$ Antibody formation against rhDNase is rare but can occur. ${ }^{2325}$ Treatment with rhDNase appears to be safe enough for more severely diseased patients. ${ }^{26}$

As with any other inhaled medication in cystic fibrosis, the therapeutic effect of rhDNase depends on using a suitable nebuliser. Considerable differences exist in aerosol qualities and respirable fraction between some of the most frequently used devices. ${ }^{27}$ With effective inhalation technique and an appropriate nebuliser, the substance reaches the bronchial secretions and, as intended, reduces their viscoelastic properties by cleaving DNA. ${ }^{28} 29$

This, however, does not necessarily mean that the biochemical effects of rhDNase are of clinical relevance. There are some theoretical caveats against extrapolating reduced viscoelastic properties of secretions into an obligatory increase in their clearance. Bronchial secretions are characterised by an optimal range of viscosity for effective mucociliary transport ${ }^{30}$ and a further reduction in viscosity could lead to a progressive mechanical uncoupling of cilia and secretions. The transport of mucus by coughing depends not only on its viscoelasticity but also on its adhesive surface properties. ${ }^{31} \mathrm{~A}$ decrease in the surface tension of mucus is 
generally associated with a decrease in its adhesive properties and a resulting increase in the transport efficacy of coughing. ${ }^{32}$ It was recently shown that DNA fragmentation by rhDNase may decrease the surface tension of mucus and thus alter its adhesive properties favourably. ${ }^{33}$ It follows that rhDNase might support cough clearance by its effects on the surface properties of mucus; at the same time, depending on the pretreatment viscosity of bronchial secretions, the substance could either enhance or reduce mucociliary clearance by its effects on viscoelasticity. While such theoretical considerations argue against a general therapeutic benefit by a reduction in viscoelasticity in all patients, further questions need to be asked from a more clinical point of view.

\section{Short term effects}

Here the question is whether rhDNase really enhances the clearance of abundant secretions. As with studies of chest physiotherapy, this effect might be demonstrated by quantifying expectorated sputum, observing the clearance of radioaerosols, recording lung function changes, and assessing the rate of relevant respiratory complications such as atelectasis. Early clinical studies to evaluate the short term effects of rhDNase all focused on lung function changes and reported significant and clinically relevant improvements in forced expiratory flow rates and volumes after a few days of treatment. ${ }^{212234}$ Intermittent treatment with rhDNase resulted in promptly improved lung function which returned to baseline levels when inhalations were discontinued. ${ }^{3}$

To investigate the theory of a cause and effect relationship between increased sputum clearance and improved lung function a correlation between the weight of expectorated sputum and the dimension of observed lung function changes must be shown and, in fact, such a correlation has been reported in inpatients with cystic fibrosis in a previous chest physiotherapy study. ${ }^{35}$ For rhDNase, however, studies of sputum weight and correlations between sputum weight and lung function have not, as yet, been performed. The extent of the changes in sputum viscoelasticity following treatment with rhDNase has been shown to correlate with changes in lung function. ${ }^{29}$ One radioaerosol study indicated a marginally improved clearance after rhDNase. ${ }^{36}$

In contrast to the lack of controlled data, many uncontrolled clinical observations have indicated that rhDNase does facilitate sputum clearance and many patients have reported that they find it much easier and more effective to raise secretions with the aid of rhDNase than without. Thus, presently established scientific evidence, together with everyday clinical experience, suggest that the observed changes in lung function are effected by enhanced clearance of secretions. It should be relatively easy to substantiate this hypothesis further in future clinical trials.

\section{Long term effects}

Here the question is whether the beneficial short term effects of rhDNase will translate into therapeutic long term effectiveness. The rationale behind expecting a beneficial effect on the course of the disease from improved clearance of secretions stems from our present understanding of the mechanisms of the disease. The proteolytic activity in the bronchial secretions of patients with cystic fibrosis is significantly increased, and this excessive proteolytic activity mainly stems from the host's own neutrophils. ${ }^{37}$ In addition to elastase, collagenase and peroxidase have recently been found in the bronchial secretions of bacterially infected patients with cystic fibrosis. ${ }^{3839}$ This proteolytic load on the airway wall affects ongoing tissue damage and, thus, progression of bronchiectasis. ${ }^{37}$ Consequently, one may expect that effective clearance of secretions should reduce this proteolytic burden and, thereby, favourably alter the course of the disease.

This hypothesis might be tested by observing long term changes in lung function, by counting acute exacerbations and hospital admissions, and by quantifying other necessary therapeutic interventions. Furthermore, any therapeutic long term effect on disease progression should improve quality of life and survival. So far, studies on the long term effects of rhDNase therapy have mainly focused on changes in lung function. These controlled and uncontrolled (observational) studies have ranged in duration from several months to two years ${ }^{23252640}$; mean improvements of more than $10 \%$ in forced expiratory volume in one second $\left(\mathrm{FEV}_{1}\right)$ have been reported for the first days of treatment but a longer duration of treatment resulted in markedly smaller positive changes. Given this reduction in the effects on lung function with time, the question arises as to whether the therapeutic effectiveness might be insignificant with extended treatment. A recently published two year study which reported an improved outcome did not contradict this speculation as it was merely observational and lacked a control group $^{40}$; furthermore, several of the most severely diseased patients in this study succumbed and thus had no statistical input into the group outcome. Another recent paediatric six month study reported large interindividual differences in the effects of rhDNase on lung function, with some patients improving while others were unchanged or even deteriorated. ${ }^{41}$

Such large interindividual differences in the long term effects of rhDNase have been observed by many cystic fibrosis caregivers. Various attempts at predicting the outcome for the individual patient on the basis of pretreatment clinical data have failed ${ }^{42}$; even assessment of the patient's daily sputum production before treatment with rhDNase did not correlate with subsequently observed effects on lung function. ${ }^{43}$ While some patients report considerable improvement in their sputum clearance and others do not, this subjective assessment also fails to correlate with objective outcome measures. ${ }^{41}$

The effects of rhDNase on lung function not only decrease with time, but may be completely lost after the medication is terminated. One six month treatment study showed that, after 
stopping rhDNase, lung function dropped markedly below the initial baseline level. ${ }^{25}$ When this pretreatment baseline value is plotted against that end point a slope of deterioration is obtained that does not differ substantially from the natural course of the disease. Concern arises as to whether treatment with rhDNase only effected a superficial removal of secretions while, deeper down on the mucosal surface, tissue damage continued as before. If so, therapy would only have effected some "lung function cosmetics" while having no impact on the long term progression of the disease. In a recently reported study, rhDNase failed to reduce the level of elastase and other inflammatory markers in the sputum and blood of patients with cystic fibrosis. ${ }^{44}$

Thus, a beneficial long term effect of rhDNase is not yet firmly established from the available literature on its effects on lung function. Less attention has been paid to other outcome measures, but one six month multicentre study found a dose-dependent tendency towards fewer acute respiratory exacerbations with rhDNase treatment. ${ }^{23}$

\section{Supportive effects}

Effective clearance of secretions should make the bronchial mucosa of patients with cystic fibrosis more accessible for other inhaled medications such as antibiotics, amiloride, topical steroids, proteinase inhibitors, and gene therapy. As with chest physiotherapy, rhDNase could thus have a potential role as a facilitator of other aerosol medications. Valid studies to support this hypothesis, however, are lacking. One radioaerosol study demonstrated a more homogeneous deposition of tracer after rhDNase. ${ }^{36}$ Recent in vitro data indicate that rhDNase might be superior to other mucolytic agents in assisting the access of liposomal gene vectors to the cell surface, ${ }^{45}$ but here the question arises as to whether or not the enzyme will damage the therapeutic DNA-liposome complex.

Another potential supportive role of rhDNase which needs to be investigated is the possibility that it improves the antibacterial efficacy of antimicrobial agents. Antibiotic binding to sputum has been described by several investigators, and sputum DNA plays an important role in this phenomenon. ${ }^{46-50}$ The few in vitro data available suggest that this binding to various sputum fractions can be reduced by adding DNase, ${ }^{51}$ which indicates the possibility of an interesting therapeutic synergism. Concern has arisen as to whether the combination of rhDNase and inhaled antibiotics could have other more adverse effects, but recently obtained results suggest that, even if this combination of inhaled substances did occasionally reach the alveolar space, the surface tension properties of pulmonary surfactant would not be significantly affected. ${ }^{52}$ In vivo findings, however, have so far remained inconclusive. A reduction in the colony density of several relevant bacterial invaders was reported in one observational study of patients with cystic fibrosis treated with rhDNase. ${ }^{53}$
Other investigators, however, did not find a significant reduction in the serum level of antiPseudomonas precipitins after one year of treatment with rhDNase. ${ }^{54}$ It follows that the possibility of rhDNase enhancing the efficacy of inhaled or systemic antibacterial medication is as yet insufficiently explored. Clearly, this potential effect of rhDNase is an interesting and important issue that calls for further study.

\section{Prescription}

If it is correct that rhDNase has some therapeutic long term effectiveness, when, in the course of the disease, should such therapy commence? Patients with full blown suppurative lung disease will certainly provide more than sufficient substrate for the enzyme. An unresolved question, however, relates to the administration of rhDNase in mildly or moderately diseased patients and those with early stages of the disorder. There are arguments both for and against early prescription.

In general, clinical and radiological assessment, as well as conventional lung function testing and sputum bacteriology, tend to underestimate the amount of bronchial inflammation and infection in patients with seemingly mild or moderate lung disease. This is illustrated by bronchoalveolar lavage studies where evidence for a neutrophil-dominated increase in cells and abundant active elastase was found in clinically stable patients with only mildly compromised lung function. ${ }^{55}$ Others observed significantly increased DNA levels in the lavage fluid of infants with cystic fibrosis. ${ }^{56}$ Based on similar lavage findings, some authors have even postulated that chronic inflammation of the bronchial mucosa may commence before bacterial infection occurs. ${ }^{57}$ While this issue remains controversial, it is clear from the recent literature that mucosal inflammation may occur surprisingly early, and these findings would argue for a liberal and early prescription policy for rhDNase in clinical practice.

Such a liberal and early prescription policy, however, will, at least in some patients, result in unnecessarily high treatment costs. In addition, it could induce antibody formation in a few patients before their disease has progressed to a stage where they would really benefit from treatment. Furthermore, the question arises as to whether rhDNase could have any untoward effects in more mildly diseased patients who have so far maintained effective mucus transport. In an in vitro study using a frog palate model, rhDNase increased the transport velocity of those cystic fibrosis sputum samples with a decreased baseline mucociliary transport rate; however, it tended to decrease mucus transport velocity when added to other sputum samples with an increased baseline transport rate. ${ }^{33}$ This finding indicates the possibility that rhDNase may occasionally have a negative effect on mucus transport in patients with only mildly damaged mucosa. The pathophysiological explanation for this negative effect could be the aforementioned mechanical uncoupling of ciliary action and the mucus layer. 
Thus, there are arguments for and against the early prescription of rhDNase. Obviously, the routine management of patients with cystic fibrosis does not provide sufficient information for a targeted and individualised indication. The question arises as to whether data from more invasive investigations such as fibreoptic bronchoscopy and bronchial lavage should be considered as a prerequisite for prescribing rhDNase to mildly and moderately diseased patients.

\section{Interaction with other therapeutic strategies}

Other strategies for clearing excess bronchial secretions have a traditional position in the management of patients with cystic fibrosis, especially the various techniques of chest physiotherapy which have been developed to match the therapeutic needs of these patients specifically. ${ }^{58}$ Although applying a mechanical rather than a pharmacological concept of treatment, chest physiotherapy pursues the same goal as rhDNase. Surprisingly, however, no clinical studies to compare the relative benefit from these two different approaches have been undertaken. One recent in vitro study demonstrated an optimal effect on sputum spinnability when rhDNase and airflow oscillations were applied concomitantly. ${ }^{59}$ In general, cystic fibrosis caregivers tend to consider chest physiotherapy and rhDNase inhalation as complementary rather than competitive, but this concept is based exclusively on uncontrolled clinical observations. However, some other clinical observations might suggest a different perspective on this issue. In some European cystic fibrosis centres doctors were surprised that chest physiotherapists were able to predict whether or not a patient would respond with an improvement in lung function to newly prescribed rhDNase. Such foresight was (and is) usually based on the physiotherapist's indepth knowledge of the particular patient's chest physiotherapy skills and compliance. Thus, one is frequently able to predict a marked therapeutic response in those patients who produce significant amounts of sputum but comply badly with their daily chest physiotherapy routine. One can speculate that those recent studies that attempted to predict the lung function response to rhDNase of patients with cystic fibrosis ${ }^{4243}$ had to fail because they did not take into account the expertise and compliance with chest physiotherapy of the subjects.

The possibility therefore remains that regular inhalations of rhDNase might effectively replace the daily chest physiotherapy routine in some patients; in others, chest physiotherapy may be more effective than rhDNase, while a third subgroup might actually benefit from the presently prevailing strategy of combining these two therapeutic approaches. Finally, one can speculate that even if maximum clearance of secretions could be achieved by chest physiotherapy alone, rhDNase would be a valuable adjunct if it made mechanical clearance less time and energy consuming. At present, however, all these speculations lack any scientific background. It follows that the relative role of physical and pharmacological clearance of the airways in patients with cystic fibrosis needs to be more clearly defined by carefully conducted clinical studies.

The role of other mucolytic agents in the management of patients with cystic fibrosis has not been clearly established. There is the theoretical possibility of combining rhDNase with other mucolytic substances in an attempt to maximise their effects on viscoelasticity. Recent in vitro results indicate that combinations with nacystelyn, gelsolin, and hypertonic saline are, in fact, more effective on the viscoelastic properties of cystic fibrosis sputum than rhDNase alone. ${ }^{60-62}$ Translating these results into a clinical experiment might, however, carry the risk of ineffective ciliary beating in the presence of large intrabronchial pools of liquefied secretions; in the presence of an additionally resulting mechanical handicap for coughing and chest physiotherapy, secretions might be shifted from one lung region to another rather than expectorated, and negative effects on the mechanics of breathing and on gas exchange might ensue.

\section{Conclusions}

In conclusion, the present widespread clinical use of rhDNase in the treatment of patients with cystic fibrosis is burdened by a range of unresolved problems and open questions. It seems the substance might have been introduced into the clinical routine too early, and this enthusiastic haste is being paid for with doubts on the ethics and cost effectiveness.

A liberal policy of prescribing rhDNase to all but the most mildly diseased patients will burden the health care system with considerable costs, will further complicate the daily therapeutic routine of patients by one more aerosol administration and, with a small but nevertheless finite risk of side effects, will be a load on the conscience of the caregiver. On the other hand, a very restrictive general prescription policy will burden the caregiver with the risk of withholding potentially valuable therapy and, in addition, such a position will be complicated by pressure towards more liberal prescription from patients, parents, and lay organisations.

A more targeted approach, based on a careful assessment of the disease in individual patients, might appear to be a more reasonable alternative; however, this remains only a theoretical option as there are no established criteria for effectively individualising treatment at present. As already mentioned, attempts at predicting the lung function response of the individual patient on the basis of sputum production and various other clinical parameters have failed. ${ }^{4243}$ Some groups promote the use of scoring systems, but these are based on arbitrarily chosen criteria and, so far, have not been validated. ${ }^{63}$ Another frequently used method to individualise the prescription of rhDNase is a short therapeutic trial with closely monitored results. As outlined above, however, an easily assessed improvement in short term 
lung function cannot be extrapolated into clinically relevant long term benefits. To rely on the patient's own subjective assessment of therapeutic efficacy is also questionable as some patients report beneficial effects even in the presence of objectively documented deterioration. ${ }^{41}$ In summary, it remains unclear whether or not treatment with inhaled rhDNase has a positive impact on the long term course of the disease; if it does, no clearly defined criteria are available to identify those who will benefit.

It seems that in many cystic fibrosis centres the initial enthusiastic welcome for a promising new substance is turning into the more sober acknowledgment of a therapeutic problem. Clearly, the present insight into the potential and limitations of inhaled rhDNase is far from complete and more studies are urgently needed.

1 FitzSimmons SC. The changing epidemiology of cystic fibrosis. F Pediatr 1993;122:1-9.

2 Range SP, Knox AJ. rhDNase in cystic fibrosis. Thorax 1995;50:321-2.

3 Hodson ME, Shah PL. DNase trials in cystic fibrosis. Eur Respir f 1995;8:1786-91.

4 Armstrong JB, White JC. Liquifaction of viscous purulent exudates by deoxyribonuclease. Lancet 1950;ii:739-65.

5 Chernick WS, Barbero FJ. Composition of tracheobronchia secretions in cystic fibrosis of the pancreas and bronchiectasis. Pediatrics 1959;24:739-45.

6 Potter J, Matthews LW, Lemm J, Spector JS. Composition of pulmonary secretions from patients with and without of pulmonary secretions from patients with and
cystic fibrosis. Am $\mathcal{F}$ Dis Child 1960;100:493-5.

7 Matthews LW, Spector S, Lemm J, Potter JL. Studies on pulmonary secretions. I. The overall chemical composition of pulmonary secretions from patients with cystic fibrosis, bronchiectasis, and laryngectomy. Am Rev Respir Dis 1963; 88:199-204

8 Picot R, Das I, Reid L. Pus, deoxyribonucleic acid, and sputum viscosity. Thorax 1978;33:235-42.

9 Lethem MJ, James SL, Marriott C. The role of mucous glycoproteins in the rheologic properties of cystic fibrosis sputum. Am Rev Respir Dis 1990;142:1053-8.

10 Lethem MJ, James SL, Marriott C, Burke JF. The origin of DNA associated with mucus glycoproteins in cystic fibrosis sputum. Eur Respir $千$ 1990;3:19-23.

11 Smith AL, Redding G, Doershuk C, et al. Sputum changes associated with therapy for endobronchial exacerbation in cystic fibrosis. F Pediatr 1988;112:547-54

12 Chernick WS, Barbero GJ, Eichel HJ. In-vitro evaluation of effect of enzymes on tracheobronchial secretions from patients with cystic fibrosis. Pediatrics 1961;27:589-96.

13 Lieberman J. Measurement of sputum viscosity in a coneplate viscometer. Am Rev Respir Dis 1968;97:662-72.

14 Elmes PC, White JC. Deoxyribonuclease in the treatment of purulent bronchitis. Thorax 1953;8:295-300.

15 Salomon A, Herschfus JA, Segal MD. Aerosols of pancreatic dornase in bronchopulmonary disease. Ann Allergy 1954; 12:71-9.

16 Spier R, Witebsky E, Paine JR. Aerosolized pancreatic dornase and antibiotics in pulmonary infection. $\mathscr{f} A M A 1961$; 178:878-86

17 Lieberman J. Dornase aerosol effect on sputum viscosity in cases of cystic fibrosis. $\mathcal{F} A M A$ 1968;205:312-3.

18 Raskin P. Bronchospasm after inhalation of pancreatic dornase. Am Rev Respir Dis 1968;98:597-8.

19 Shak S, Capon DJ, Hellmiss R, Marsters SA, Baker CL. Recombinant human DNase I reduces the viscosity of cystic fibrosis sputum. Proc Natl Acad Sci USA 1990;87: 9188-92.

20 Aitken ML, Burke W, McDonald G. Recombinant human DNase inhalation in normal subjects and patients with cystic fibrosis. Phase 1 study. $\mathscr{F A M A} 1992 ; 267: 1947-51$.

21 Hubbard RC, McElvaney NG, Birrer P, et al. A preliminary study of aerosolized recombinant human deoxy-
ribonuclease I in the treatment of cystic fibrosis. $N$ Engl f Med 1992;326:812-5.

22 Ramsey BW, Astley SJ, Aitken ML, et al. Efficacy and safety of short-term administration of aerosolized recombinant of short-term administration of aerosolized recombinant
human deoxyribonuclease in patients with cystic fibrosis. human deoxyribonuclease in patients

23 Fuchs HJ, Borowitz DS, Christiansen DH, et al. Effect of aerosolized recombinant human DNase on exacerbations of respiratory symptoms and on pulmonary function in of respiratory symptoms and on pulmonary function in
patients with cystic fibrosis. $N$ Engl $f$ Med 1994;331: patients

24 Bryson HM, Sorkin EM. Dornase alfa. A review of its pharmacological properties and therapeutic potential in cystic fibrosis. Drugs 1994;48:894-904.

25 Shah PL, Scott SF, Fuchs HJ, Geddes DM, Hodson ME Medium term treatment of stable stage cystic fibrosis with recombinant human DNase I. Thorax 1995;50:333-8. 26 Shah PJ, Bush A, Canny GJ, et al. Recombinant human
DNase I in cystic fibrosis patients with severe pulmonary disease: a short-term, double-blind study followed by six months open-label treatment. Eur Respir ₹ 1995;8:954-8. 7 Shah PL, Scott SF, DeSouza L, Nazir T, Marriott C, Hodson ME. Assessment of two nebuliser systems for rhDNase. Pediatr Pulmonol 1995; Suppl 12:237.

28 Brandt $T$, Breitenstein S, vonderHardt $H$, Tümmler B. DNA concentration and length in sputum of patients with cystic fibrosis during inhalation with recombinant human DNase. Thorax 1995;50:880-2.

29 Shah PL, Scott SF, Knight RA, Marriott C, Hodson ME. The effects of recombinant human DNase I on sputum rheology. Eur Respir $\mathcal{F}$ 1995;8(Suppl 19):512s.

30 Puchelle E, Zahm JM, Quemada D. Rheological properties controlling mucociliary frequency and respiratory mucus transport. Biorheology 1987;24:557-63.

31 King M, Zahm JM, Pierrot D, Vaquez-Girod S, Puchelle E. The role of mucus gel viscosity, spinnability and adhesive properties in clearance by simulated cough. Biorheology 1989;26:737-45.

32 DeBentzmann SG, Pierrot D, Fuchey C, Zahm JM, Morancais JL, Puchelle E. Distearoyl phosphatidylglycerol liposomes improve surface and transport properties of cystic fibrosis mucus. Eur Respir $\mathcal{F}$ 1993;6:1156-61.

33 Zahm JM, deBentzmann SG, Deneuville E, et al. Dosedependent in vitro effect of recombinant human DNase on rheological and transport properties of cystic fibrosis respiratory mucus. Eur Respir $\mathcal{F}$ 1995;8:381-6.

34 Ranasinha C, Assoufi B, Shak S, et al. Efficacy and safety of short-term administration of aerosolized recombinant human DNase I in adults with stable stage cystic fibrosis. Lancet 1993;342:199-202.

35 Oberwaldner B. Theißl B, Rucker A, Zach MS. Chest physiotherapy in hospitalized patients with cystic fibrosis: a study of lung function effects and sputum production. Eur Respir f 1991;4:152-8.

36 Laube BL, Auci RM, Shields DE, Christiansen D, Fuchs HJ, Rosenstein BJ. A randomized, placebo-controlled trial of the effect of recombinant human DNase I (rhDNase) on the deposition homogeneity and mucociliary clearance of radioaerosol in patients with cystic fibrosis. Pediatr of radioaerosol in patients with
Pulmonol 1993;Suppl 9:155-6.

37 Zach MS. Lung disease in cystic fibrosis - an updated concept. Pediatr Pulmonol 1990;8:188-202.

38 Power C, O'Connor CM, Macfarlane D, O'Mahoney S, Gaffney $\mathrm{K}$, Hayes J, et al. Neutrophil collagenase in sputum from patients with cystic fibrosis. Am $\mathcal{F}$ Respir Crit Care Med 1994;150:818-22.

39 Regelmann WE, Siefferman CM, Herron JM, Elliott GR, Clawson CC, Gray BH. Sputum peroxidase activity correlates with the severity of lung disease in cystic fibrosis. Pediatr Pulmonol 1995;19:1-9.

40 Shah PL, Scott SF, Geddes DM, Hodson ME. Two years experience with recombinant human DNase I in the treatment of pulmonary disease in cystic fibrosis. Respir Med 1995;89:499-502.

41 Davies J, Trindade $M$, Wallis C, Rosenthal M, Bush A. Audit of the effects of rhDNase in children with cystic fibrosis. Eur Respir f 1995;8(Suppl 19):512s.

42 Wojnarowski C, Eichler J, Frischer T, Storm K, Renner S, Götz M. Rh-DNase therapy in patients with CF: is it possible to predict lung function improvement? Pediatr possible to predict lung function
Pulmonol 1995;Suppl 12:236.

43 Romano L, Calvi A, Gaiero A, et al. Mid-term response to treatment with rhDNase can not be anticipated on the basis of sputum production. Pediatr Pulmonol 1995;Suppl 12:237.

44 Costello C, Hayes J, O'Connor C, Fitzgerald MX. Effect of nebulized recombinant DNase on mediators of inflammation in cystic fibrosis. Am $\mathcal{F}$ Respir Crit Care Med 1995;151:A20.

45 Stern M, Caplen NJ, Sorgi F, Huang L, Gruenert DC, Geddes DM, et al. The effect of mucolytic agents on liposome-mediated gene transfer across a cystic fibrosis sputum barrier in vitro. Pediatr Pulmonol 1995;Suppl 12: 222

46 Potter JL, Mathews LW, Spector S, Lemm J. Complex formation between basic antibiotics and deoxyribonucleic acid in human pulmonary secretions. Pediatrics 1965;36: 714-20.

47 Davis SD, Bruns WT. Effects of sputum from patients with cystic fibrosis on the activity in vitro of five antimicrobial
drugs on Pseudomonas aeruginosa. Am Rev Respir Dis drugs on Pseudo

48 Levy J, Smith AL, Kenny MA, Ramsey B, Schoenknecht FD. Bioactivity of gentamycin in purulent sputum from patients with cystic fibrosis or bronchiectasis: comparison with activity in serum. F Infect Dis 1983;108:1069-76.

49 Mendelman PM, Smith AL, Levy J, Weber A, Ramsey B Davis RL. Aminoglycoside penetration, inactivation, and efficacy in cystic fibrosis sputum. Am Rev Respir Dis 1985; 132:761-5.

50 Ramphal R, Lhermitte $M$, Filliat $M$, Roussel P. The binding of anti-pseudomonas antibiotics to macromolecules from
cystic fibrosis sputum. $\mathcal{F}$ Antimicrob Chemother 1988;22: cystic fibs 90 .

51 Bataillon V, Lhermitte M, Lafitte JJ, Pommery J, Rousse s. The binding of amikacin to macromolecules from the sputum of patients suffering from respiratc
Antimicrob Chemother 1992;29:499-508.

52 Clayton R, Wolfson M, Shaffer T, Shidiow D. Effect of recombinant human DNase and tobramycin on pulmonary surfactant. Pediatr Pulmonol 1995;Suppl 12:235.

53 Shah PL, Scott S, Knight RA, Hodson ME. Quantitative changes in sputum microbiology following treatment of 
stable cystic fibrosis patients with aerosolized recombinant human DNase I. Pediatr Pulmonol 1993;Suppl 9:265.

54 Munck A, Mariani P, LeBourgeois $M$, et al. Follow up of anti pseudomonas precipitins in cystic fibrosis patients treated by aerosolized Rh-DNase. Abstracts of the 20th European Cystic Fibrosis Conference, Brussels, June 1995, P88.

55 Konstan MW, Hilliard KA, Norvell TM, Berger M. Bronchoalveolar lavage findings in cystic fibrosis patients with stable, clinically mild lung disease suggest ongoing infection and inflammation. Am $\mathcal{F}$ Respir Crit Care Med 1994;150:448-54

56 McCubbin MM, Meyer K, Fick RB, Balough K. DNA levels are increased in bronchoalveolar lavage fluid from levels are increased in bronchoalveolar lavage fluid from young cystic fibrosis patients with minimal

57 Balough K, McCubbin M, Weinberger M, Smits W, Ahrens $R$, Fick $R$. The relationship between infection and inflammation in the eaply stages of lung disease from cystic fibrosis. Pediatr Pulmonol 1995;20:63-70.
58 Zach MS, Oberwaldner B. Chest physiotherapy - the mechanical approach to antiinfective therapy in cystic fibrosis. Infection 1987;5:381-4.

59 Dasqupta B Tomkiewicz RP, Boyd WA, Brown NE, King $M$. Effects of combined treatment with rhDNase and airflow oscillations on spinnability of cystic fibrosis sputum in vitro. Pediatr Pulmonol 1995;20:78-82.

60 Tomkiewicz RP, DeSanctis GT, Boyd WA, King M. Mucolytic synergism in cystic fibrosis (CF) sputum with combined rhDNase and gelsolin treatment. Am $\mathcal{F}$ Respir Crit Care Med 1995;151:A19.

61 Dasgupta B, King M. Mucolytic synergism combining rhDNase and nacystelyn in vitro in cystic fibrosis sputum. Eur Respir ₹ 1995;8(Suppl 19):512s.

62 Tomkiewicz RP, Brown NE, King M. Combined effects of hypertonic saline and rhDNase on cystic fibrosis sputum in vitro. Pediatr Pulmonol 1995;Suppl 12:236.

63 Böllert FCE, McArthur DA, Greening AP, Innes JA. Targeted introduction of DNase in Scotland. Pediatr Pulmonol 1995;Suppl 12:236 